NASA Technical Memorandum 104475

AIAA 91-2581

\title{
Results From Computational Analysis of a Mixed Compression Supersonic Inlet
}

J.D. Saunders

Lewis Research Center

Cleveland, Ohio

and

T.G. Keith

Ohio Aerospace Institute

Brook Park, Ohio

Prepared for the

27th Joint Propulsion Conference

cosponsored by the AIAA, SAE, ASME, and ASEE

Sacramento, California, June 24-27, 1991 


\title{
RESULTS FROM COMPUTATIONAL ANALYSIS OF A MIXED COMPRESSION SUPERSONIC INLET
}

\author{
J. D. Saunders* \\ NASA - Lewis Research Center \\ Cleveland, Ohio \\ T.G. Keith Jr.** \\ The Ohio Aerospace Institute \\ Brookpark, Ohio
}

\begin{abstract}
$\underline{\text { Abstract }}$
A numerical study was performed to simulate the critical flow through a supersonic inlet. This flow field has many phenomena such as shock waves, strong viscous effects, turbulent boundary layer development, boundary layer separations and mass flow suction through the walls, (bleed). The computational tools used in this study were two full NavierStokes (FNS) codes.. The supersonic inlet that was analyzed in this study is the Variable Diameter Centerbody, (VDC), inlet. This inlet is a candidate concept for the next generation supersonic transport. Application of the code to the inlet geometry involved effort in generating an efficient grid geometry and specifying boundary conditions, particularly in the bleed region and at the outflow boundary.. Results for a critical inlet operation compare favorably to Method of Characteristics predictions and experimental data.
\end{abstract}

\section{Nomenclature}

Principal Symbols:

Unless specified otherwise, all variables are non-dimensionalized.

\begin{tabular}{|c|c|}
\hline A & flow area, $\mathrm{m}^{2}\left(\mathrm{ft}^{2}{ }^{2}\right)$ \\
\hline $\mathrm{A}_{\mathrm{c}}$ & capture area, \\
\hline & $0.7073 \mathrm{~m}^{2}\left(7.61 \mathrm{ft}^{2}\right) \mathrm{TF}-30$ size \\
\hline & $0.1400 \mathrm{~m}^{2}\left(1.51 \mathrm{ft}^{2}\right) \mathrm{J}-85$ size \\
\hline$c_{p}$ & specific heat at constant pressure \\
\hline $\mathrm{d}$ & $\begin{array}{l}\text { height from surface to center of } \\
\text { total pressure tube, } \mathrm{m} \text { (ft.) }\end{array}$ \\
\hline $\mathrm{E}_{\mathrm{T}}$ & total energy per unit volume, \\
\hline $\mathrm{k}$ & effective thermal conductivity coefficient \\
\hline $\mathrm{H}$ & annulus height at local diffuser station, $\mathrm{m}$ (ft.) \\
\hline h & distance from surface, $\mathrm{m}(\mathrm{ft}$.) \\
\hline $\mathrm{L}$ & length, $\mathrm{m}(\mathrm{ft})$. \\
\hline M & Mach number \\
\hline
\end{tabular}

\footnotetext{
$*$ Aeronautical Engineer

** Director for Research,

Associate Fellow AIAA

Copyright (C) 1991 by the American Institute of Aeronautics and Astronautics, Inc. No copyright is asserted in the United States under Title 17, U.S. Code. The U.S. Govemment has a royalty-free license to exercise all rights under the copyright claimed herein for Governmental purposes. All other rights are reserved by the copyright owner.
}

$\begin{array}{ll}\mathrm{P} & \text { pressure, } \mathrm{N} / \mathrm{m}^{2} \text { (psf) } \\ \mathrm{p} & \text { static pressure } \\ \mathrm{Pr} & \text { Prandtl number } \\ \mathrm{R} & \text { Gas constant } \\ \mathrm{R}_{\mathrm{c}} & \text { inlet capture radius, } \\ & \quad 0.4745 \mathrm{~m}(18.68 \mathrm{in} .) \mathrm{TF}-30 \text { size } \\ & \quad 0.2116 \mathrm{~m} \text { ( } 8.331 \text { in.) } \mathrm{J}-85 \text { size } \\ \mathrm{r} & \text { radius, } \mathrm{m} \text { (ft.) } \\ \mathrm{Re} & \text { Reynolds number } \\ \mathrm{t} & \text { time } \\ \mathrm{T} & \left.\text { Temperature, K( }{ }^{\circ} \mathrm{R}\right) \\ \mathrm{u}, \mathrm{v}, \mathrm{w} & \text { Velocities in the } \mathrm{x}, \mathrm{r} \text { and swirl directions } \\ \mathrm{X} & \text { axial direction, } \mathrm{m} \text { (ft.) } \\ \mathrm{x} & \text { axial direction } \\ \gamma & \text { ratio of specific heats } \\ \theta & \text { circumferential angle } \\ \lambda & \text { second coefficient of viscosity } \\ \mu & \text { viscosity coefficient } \\ \rho & \text { static density } \\ \tau & \text { shear stress }\end{array}$

Subscripts:

\begin{tabular}{|c|c|}
\hline bl & centerbody bleed \\
\hline by & bypass \\
\hline & capture \\
\hline$f$, ex & diffuser exit or \\
\hline & compressor face station \\
\hline If, $\infty$ & freestream \\
\hline & laminar \\
\hline lax & maximum \\
\hline & minimum \\
\hline & reference or normalizing conditions \\
\hline & turbulent \\
\hline & local \\
\hline
\end{tabular}

\section{Introduction}

This study's goal is to accurately predict critical inlet operation with an advanced computational tool. The main challenge to accomplish this goal is the accurate modeling of the inlet's throat bleed region. Additionally this work demon- 
strates the capabilities of a new 'general purpose' fluid flow solver, PROTEUS, for use in analyzing inlet performance.

The inlet of a supersonic cruise aircraft is a crucial element in an efficient propulsion system. The inlet compresses the flow entering the engine with shock waves. For good performance, a supersonic cruise inlet is designed to compress the freestream flow to a nearly sonic Mach number, (M1.2 to M1.3), at the inlet's minimum cross-sectional area or throat. Inherent in this compression process are disturbances in the airflow along the walls of the inlet, a problem known as shock wave/boundary layer interaction. Due to the critical Mach number in the throat, even a slight disturbance can radically alter the inlet flow, i.e. inlet 'unstart' or even 'buzz'. 'Unstart' or 'buzz' are inlet conditions in which the normal shock in the throat has been expelled forward in front of the inlet and becomes highly unsteady. To keep the flow well conditioned at critical inlet operation, the disturbed airflow is removed through small openings in the inlet walls in a process known as 'bleed'. In short, an efficient supersonic inlet could not operate without bleed. Due to the complexity of the airflow, design of inlet 'bleed' is largely based on empirical guidelines.

To develop a better understanding of the flow complexities, a detailed test program and a computational solution to the complete fluid flow equations is needed. In fact, this study is specifically targeted at the Variable Diameter Centerbody, (VDC), Inlet which is a design for which experimental data exists and future wind tunnel testing is planned. The VDC inlet was designed for a M2.5 cruise passenger transport. Computational analysis tools used to prepare for wind tunnel testing has and will impact the understanding the inlet flowfield.

The application of Computational Fluid Dynamics, (CFD), to the problems in supersonic inlet flow was begun with Euler solvers over twenty years ago. The inlet in the present study was in fact designed with the aid of a Method of Characteristics code, reference 5. Further progress in applying CFD to the strongly viscous flow field in the throat and diffuser of supersonic inlets was delayed until the development of full Navier-Stokes, (FNS) codes and much faster computers became available. Some successful studies have been made in this area but are limited because they require experimentally derived knowledge of the bleed flow rates and/or pressure distribution in the bleed area. These efforts take a traditional approach to modeling the bleed flow by setting boundary conditions at the wall that allow flow to exit the computational domain, references 12 to 17 .

Two studies have taken a different approach by actually solving the flow from the throat through the wall boundary layer into the bleed slot, references 18 and 19. This approach is very time-consuming but has shown some insight into the bleed flow region. The conclusion is that bleed cannot be modeled by simple boundary conditions. The insight from this work can be used to devise more accurate albeit complicated boundary conditions. This insight will be used to guide bleed modeling in this study.
Beyond the scope of this work, the ultimate goal is to use CFD as a tool to investigate the 'goodness' of various inlet designs. With several orders of magnitude increase in computer capability or algorithm speed, (in perhaps 5 years maybe 50?), inlet design may be accomplished largely on a computer with wind tunnel testing used only for verification purposes.

\section{Background}

\section{A. Variable Diameter Centerbody}

The Variable Diameter Centerbody, (VDC), inlet is an ongoing research program at the Lewis Research Center. The VDC inlet is a mixed compression, axisymmetric inlet that has potential application on the next generation supersonic transport. This inlet was identified as one of the most promising axisymmetric concepts for supersonic cruise aircraft during the SCAR program in the late 1970's, reference 7. Some of its features include high recovery, low bleed, good angle-of-attack tolerance and excellent engine airflow matching. These features have been demonstrated at Lewis in the past by the design and testing of fixed hardware models, references 1 to 4 . A current test program in the LeRC 10'x10' Supersonic Wind Tunnel, (SWT), will attempt to duplicate these features on flight-like hardware that actually incorporates the variable geometry.

An outcome of the supersonic cruise research (SCR) program identified the VDC inlet as an important technology thrust to continue funding, reference 6 . It is an axisymmetric inlet with $45 \%$ internal contraction ratio needed for high performance at its design cruise Mach number of 2.5 , figure 1. Other aspects of the inlet design include the variable

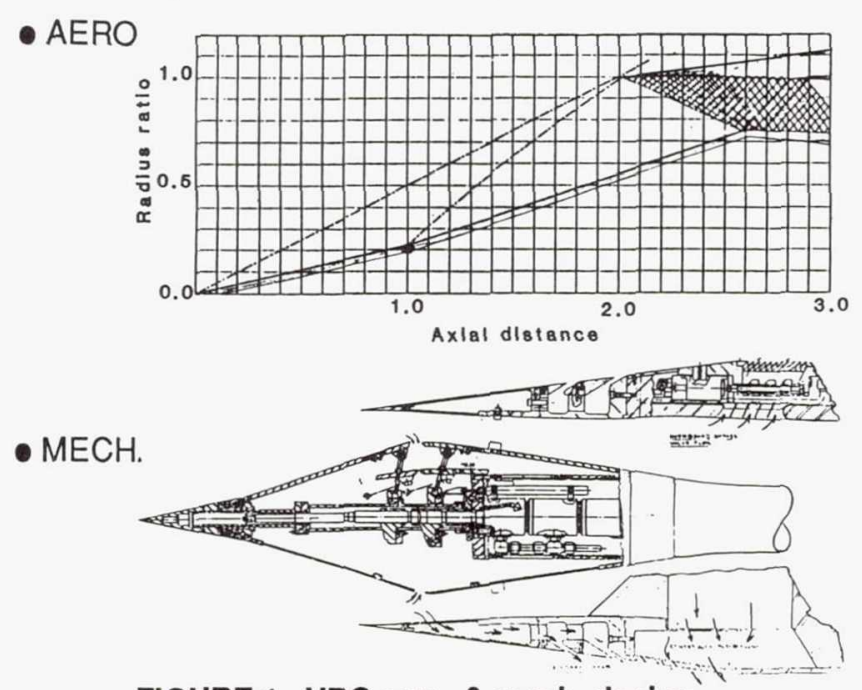

FIGURE 1., VDC aero. \& mech. design

diameter centerbody and a focussed cowl compression on a slotted bleed region in the centerbody. The variable diameter centerbody allows large variations in throat area and airflow to provide good compatibility with the engine. The focussed cowl compression minimizes bleed flow require- 
ments and reduces the inlet length and resulting weight. Aerodynamic testing of the concept was done with fixed hardware in the early 1970's and verified the high expected performance of this concept. An schematic view of this model is shown in figure 2 . The model had centerbody and

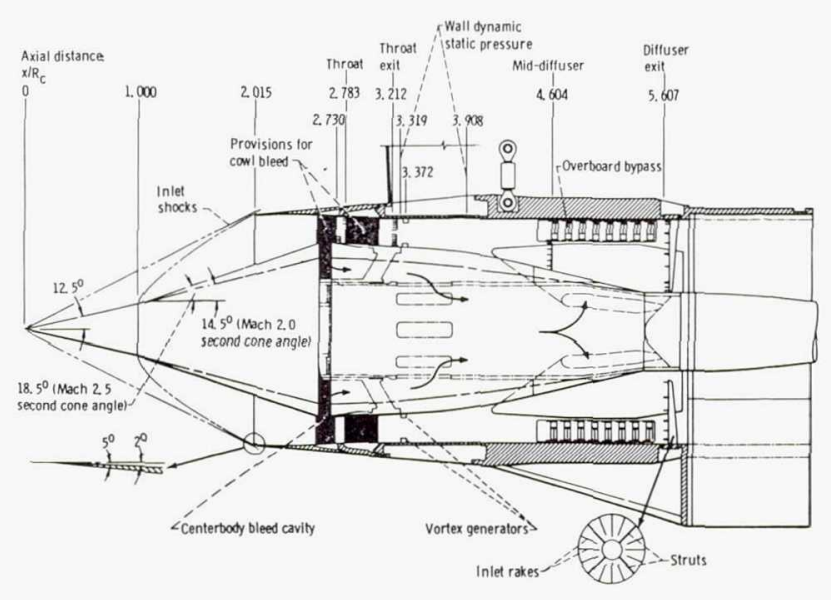
FIGURE 2., Fixed-hardware model,
schematic view

cowl bleed for performance and shock stability and overboard bypass air for engine matching. Vortex generators were installed downstream of the throat to prevent separation in the subsonic diffuser. This model was tested in the LeRC 10 'x 10 ' Supersonic Wind Tunnel at Mach numbers of 2.5 and 2.0. For economic reasons the mechanical design of that test inlet was simplified to incorporate fixed centerbody configurations. The fixed-hardware inlet model was sized and tested with a TF-30 turbofan engine. The cowl lip radius, $R_{c}$, was 18.68 inches. A photo of the model installed in the $10^{\prime} \times 10^{\prime}$ SWT is shown in figure 3

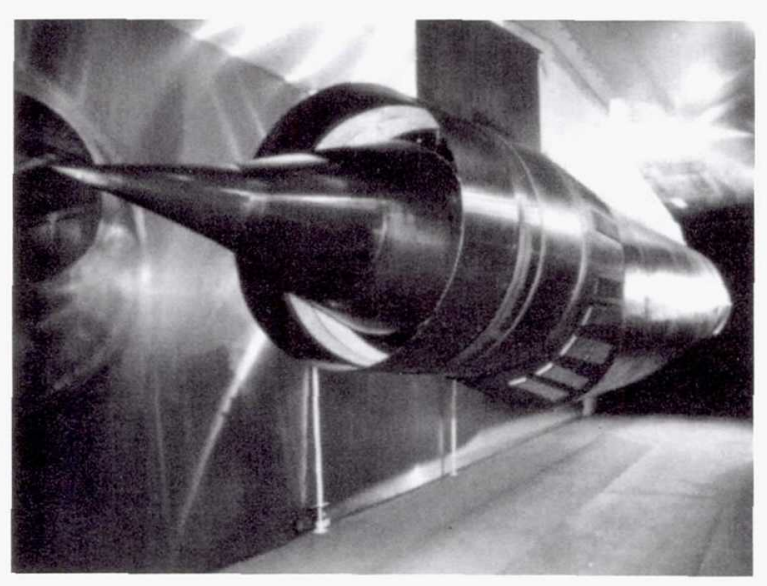

FIGURE 3., Fixed-hardware model, installed in 10'x10' SWT

The essential features of the inlet design incorporate a bicone centerbody of $12.5^{\circ}$ and $18.5^{\circ}$ half angle cones and an initial internal cowl angle of $2^{\circ}$. The design philosophy for this mixed compression inlet is to utilize a bicone spike to provide the maximum external compression compatible with high total pressure recovery and low cowl drag. As a result, 45 percent of the supersonic area contraction is internal for the Mach 2.5 design condition.

Mechanical design of the VDC inlet with the variable geometry began in 1982 and a complete set of drawings was finished in mid-1984. Unfortunately, programmatic restructuring canceled the program with only a fraction of the hardware fabricated or procured. The High Speed Research program has revived interest in a commercial supersonic aircraft in general and this inlet program in particular. The test program in the LeRC $10^{\prime} \times 10^{\prime}$ SWT is slated to begin in the summer of 1992.

The VDC inlet incorporates an umbrella-like mechanism to create a variable diameter centerbody, figure 1 . The variable-hardware model is sized for a J-85 turbojet engine and is less than half the size of the fixed-hardware model, $\mathrm{R}_{\mathrm{c}}=8.31$ ". The supersonic diffuser of the J-85 sized VDC inlet is geometrically scaled from the fixed hardware model. The subsonic diffusers are slightly different.

This analytical study was undertaken, in part, to prepare for the experimental test program. Input for the analysis was setup for the fixed-hardware, TF-30 sized, inlet. Comparison between experimental test results from the fixed geometry model and various computational fluid dynamic analyses will be made.

\section{B. PROTEUS Code}

A computer code, called PROTEUS, is used to solve the two-dimensional, axisymmetric, Reynolds-averaged, steady compressible Navier-Stokes equations for the flow through the VDC inlet at its design Mach number of 2.5. The PROTEUS code was developed for aerospace propulsion applications and was designed to be easy to use and modify. Code readability, modularity, and documentation were emphasized in developing PROTEUS, reference 8.

The governing equations are written in Cartesian coordinates and transformed into generalized nonorthogonal body-fitted coordinates. They are solved for this application by marching in time using a fully-coupled alternatingdirection-implicit solution procedure with generalized first order time differencing. The boundary conditions are implicit and all terms, including the diffusion terms, are linearized using second-order Taylor series expansions. Turbulence is modeled using a Baldwin-Lomax based algebraic eddy viscosity model.

The program has many options which may be selected through an input file. For this study both Euler solutions and full Navier-Stokes solutions were obtained. The energy equation was eliminated through the assumption of constant total enthalpy. Explicit nonlinear artificial viscosity was 
used to damp the pre- and post-shock oscillations in the supersonic regions of the flow. The computational grid was generated external to the PROTEUS code due to the complexity of the inlet geometry.

The PROTEUS code has many options not discussed here but fully documented in reference 8 . This reference covers the analytical development, user application with test cases, and detailed program information of the code. One of the main capabilities of the code not used in this study is that it can be used in a 'time-accurate' mode for unsteady flows by using second order finite differencing in time. Future capabilities in progress are a three-dimensional version of the code. Also in the planning stages are a multi-blocked version allowing a flow field to be broken up into many grids. This allows problems requiring a large number of grid points to be solved as a series of smaller interacting problems on computers with finite memory resources. Blocking also relieves the waste of gridding non-flow areas such as struts.

\section{C.}

\section{PARC Code}

The PARC code is a well established full Navier-Stokes code originally developed at Arnold Engineering Development Center as a general purpose robust code to reduce the costs and risks in test planning, execution and analysis, reference 9. Subsequent use has included inlet and nozzle analyses done at NASA-Lewis. In many respects, the code is similar to PROTEUS so that much of the initial setup could be directly transferred to the PARC code analysis. In fact, the PARC code analysis was begun using solution and grid files from the PROTEUS analysis. As such, only the major differences between the codes will be pointed out here.

The algorithms within the flow solvers of the two codes differ somewhat. The PROTEUS code essentially uses the Beam-Warming formulation that must solve a blocked pentadiagonal set of matrices to advance the solution in time. Using Pulliam's approach, the PARC algorithm begins with this setup, factors and uses LU, (Lower-Upper), decomposition on the matrices to reduce the complexity of the solution. This approach is inherently faster than the algorithm used by the PROTEUS code and offers a factor of 2 increase in speed for the present application. In addition, the PARC coding is tailored for the CRAY supercomputer and takes six times less memory to run the present application. While both codes have options to provide 'general' boundary conditions, the PARC input is tailored to set large regions of the boundary to the same condition while PROTEUS allows grid point by point specification of the individual thermodynamic quantities. This difference is most apparent for the bleed boundary condition where the overall massflow through the region is specified in the PARC code while a velocity profile can be specified with the PROTEUS code.

The standard turbulence model in the PARC code, just like the PROTEUS code, is the Baldwin-Lomax model. An alternative version of the code includes the two-equation $\mathrm{K}$ - e model which handles boundary layer history effects. For certain applications with flow separations, the more complicated K-e model has proven superior to algebraic models, reference 10. The $\mathrm{K}$-e version of the PARC code is more computationally intensive per time-step. But with the better turbulence model, the solution may converge faster and thereby partially offset the slower time-steps.

Another major difference between the codes deals with their time-accurate features. PROTEUS was conceived with time-accuracy in mind; while only recently were input options added to the PARC code to calculate time -accurate flows. This PARC option actually uses a 'pseudo' RungeKutta algorithm and is significantly slower than the standard Thomas algorithm. In either case, detailed comparison of unsteady flow solutions to experiment have not been reported. Work is actively being pursued to simulate an unsteady transonic diffuser flow with the PROTEUS code, however. In the present application, no attempt was made to use the time- accurate options of either code. Unsteady flows were simulated using the standard first-order timeaccuracy of the codes with a globally constant time-step.

\section{Application - Supersonic Inlet Analysis}

This section describes both the initial preparation and the iterative process necessary to evolve a solution for the VDC inlet flowfield. First a discussion of the general procedure is given. More detailed discussions of the flowfield boundary conditions and the computational grid development are then presented. The care taken in selecting the boundary conditions and grid and the procedure used to evolve the solution has a dramatic influence on the quality and speed of the results.

\section{A. Procedure}

The study initially began by using the PROTEUS code with laminar viscosity. The initial flow field was set to Mach 2.5 freestream conditions throughout the flow field and zero velocities at the inlet's centerbody and cowl. The compressor face boundary is initially set as an extrapolation condition. This setup should allow the inlet shocks to develop, the flow to compress nearly to critical conditions in the throat and then reaccelerate to supersonic conditions down through the diffuser and out the compressor face boundary. Once this flow solution reaches steady state conditions, various levels of outflow "back" pressure are applied to position the normal shock downstream of the throat.

This back-pressuring process is not straight forward. Since the change in back-pressure, (or any boundary condition change), occurs across some element of computational time, the change is an inherently unsteady event. Essentially, a change in pressure corresponds to an increase in momentum 
due to the suddenness or acceleration of pressure change. If the pressure change occurs over a single iteration step as it does with the PARC code, a large transient shock forms whose strength is inversely proportional to the computational time-step. This shock is analogous to an inlet hammershock that occurs in real supersonic inlet-engine systems when the engine stalls, references 20 to 22 . Hammershock over-pressure, or transient pressures greater than freestream total pressure, develop behind the shock. If the transient is powerful enough, the inlet will unstart. Increasing the outflow boundary pressure must be done carefully and incrementally to avoid hammershock unstarts.

A final note on procedure is needed to help define convergence to steady-state. Traditional levels of measured steady state flow convergence, (i.e. L2 residual reduction), were not reached in this application. This fact is due to the natural unsteadiness associated with strong shock turbulent boundary layer interactions. A global measure of convergence, mass flow conservation, was used in this study as well as other inlet studies, reference 16. Most of the computational time is required in positioning the terminal shock in the subsonic diffuser with the proper amount of back-pressure. The solution was examined periodically to check shock position and transient shock-induced oscillations. This examination often resulted in interactive adjustments of time-stepping, artificial viscosity and exit pressure.

\section{B. General Boundary Conditions}

For both the PROTEUS and PARC code the input boundary conditions were identical with the exception of the bleed slot boundary. The computational domain and boundary conditions are shown in figure 4 . The flow was simulated
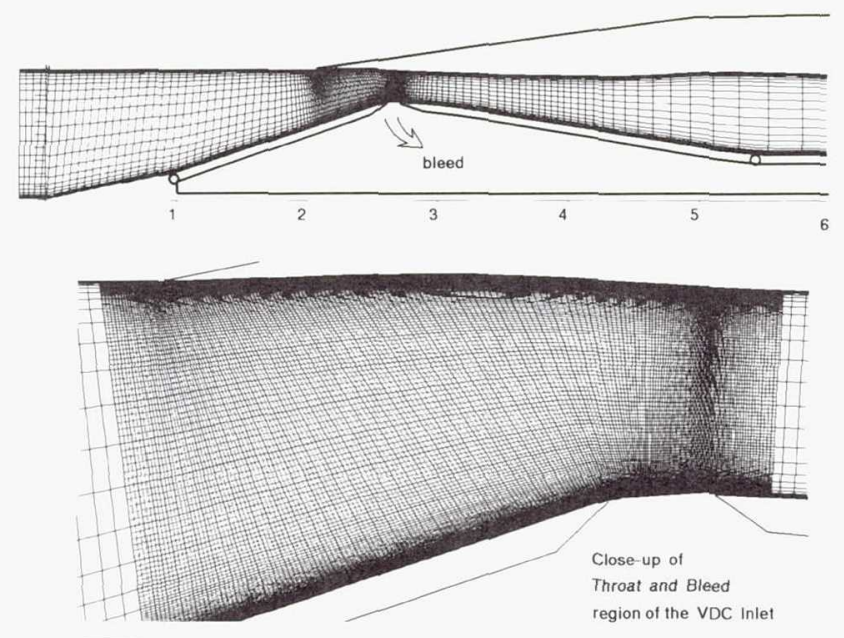

FIGURE 4., Computational grid fine mesh, $447 \times 199$ points

slightly ahead of the inlet centerbody spike, (the inflow plane), downstream to the location of an engine compressor face, (the outflow plane). The inflow plane is set to uniform freestream conditions. The outflow plane has an extrapola- tion boundary condition set initially. This allows the computed flow to reaccelerate to supersonic conditions through the outflow plane. The top and bottom contours are dictated by the centerbody and cowl internal wall surfaces. No slip wall boundary conditions are applied to these surfaces for the full Navier-Stokes solutions, while slip walls are applied for Euler solutions. The freestream boundary ahead of the cowl was simply set to the cowl lip radius and carried forward to the inflow plane. An extrapolation boundary condition was applied here allowing the centerbody spike shocks to exit the computational domain with minimal reflection. For the axis of symmetry boundary that runs between the inflow plane and the centerbody spike, some difficulty with the PROTEUS code was encountered when the radius was set equal to zero. Consequently, a small diameter cylinder of $1 \%$ of the cowl lip radius was artificially added to the geometry. The cylinder eliminates the $\mathrm{R}=0$. line from the computational domain and allowed the calculation to proceed. This geometry alteration was kept for the grid used with the PARC code.

The inlet's slotted bleed region was on the centerbody from $x / R_{c}=2.5831$ to $x / R_{c}=2.6883$. From a previous inlet bleed study, reference 15 , the proper boundary condition for the bleed region was crucial to even obtain convergence in the solution. Of course, the accuracy in the flow solution was very sensitive to this boundary condition since it cut through flow with high pressure and velocity gradients.

The implementation of bleed differs between the two codes used. In the PROTEUS code, individual grid point boundary conditions may be specified. The laminar bleed study done by Hamed, reference 19, gave profiles across the slot of tangential and normal velocity. This profile was used to specify the individual velocity components in the bleed slot region.

For the PARC code a more restrictive boundary condition is applied over the entire bleed slot by setting a mass flow. The PARC code then sets a constant exit pressure over the entire slot length to deliver this mass flow. Errors in the calculated mass flow versus the input mass flow are used to adjust the exit pressure for the next iteration. This boundary condition is more restrictive than the one use in the PROTEUS code for the following reason. As a disturbance such as a shock traverses the bleed slot and causes a change in bleed mass flow, the PARC condition will try to maintain a constant mass flow while the PROTEUS condition will allow changes. This becomes important when the terminal shock is positioned by setting a compressor face pressure.

\section{Inlet Geometry/ Gridding}

To adequately resolve the various shock, boundary layer, separation, and bleed phenomena and their mutual interactions, a fairly fine mesh was required to analyze this inlet. Initially, the PROTEUS code's grid size limitation was 99x99. This was increased to $149 \times 99$ as a coarse mesh and to $447 \times 199$ as a fine mesh for this study. For the Proteus code, the coarse grid required about 3 million words, 
(3Mwords), while the fine grid required nearly 20Mwords of memory storage. The PARC code has more efficiency array utilization and required only about $3 \mathrm{Mwords}$ of memory for the fine grid. The coarse mesh cases were run on the LeRC Cray X-MP and Y-MP computers while the fine mesh cases were run on the Y-MP. With the coarse mesh, only 3 points would be placed in the bleed slot region of the inlet throat with a uniform axial mesh. More grid was needed in this critical region to correctly model the complex flow phenomena. To accomplish this task, a simple two-dimensional algebraic grid generating program was written and used to adapt the mesh by packing and skewing control features.

To make efficient use of the available number of grid points, shocks were resolved over a minimum physical space by skewing the grid along their expected positions. The remaining grid points were packed in the inlet throat and, in particular, the bleed region.

To adapt the grid, the computational domain was sectioned into various regions. For example, figure 5 shows five regions: the freestream, the centerbody shocks, the precowl, the cowl shock-throat-bleed, and the subsonic diffuser sections. Each of these regions have differing grid require-

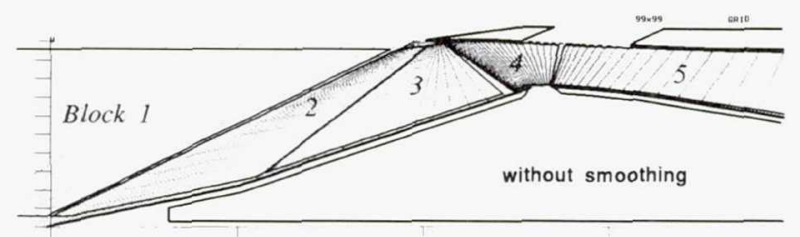

FIGURE 5., Blocking scheme to generate packed and skewed mesh.

ments. The freestream and pre-cowl sections need minimal grid since the flow is uniform or nearly uniform within them. The centerbody shocks region needs moderate gridding packed near the inflow and outflow boundaries to resolve the shocks. The cowl shock-throat-bleed region needs maximum packing to resolve the shock/boundary layer/bleed interaction. Finally, the subsonic diffuser needs moderate gridding packed on the upstream boundary.

The sectioning of the computational domain occurs by specifying quadrilaterals. Each section must have a side coincident with: an inflow and outflow crossplane, the cowl surface, and the centerbody surface. Grid lines can be set up along expected shock wave positions by skewing the inflow and outflow crossplanes. Control coefficients for the inflow cowl point and centerbody point determine packing within a section. The outflow packing is faired with the downstream sections inflow control coefficients. By packing the inflow and outflow crossplanes, the center of the section becomes sparse and vice versa.

This scheme results in a distribution of crossplane end points defining the geometry of the computational domain, the packing and the skewness. Finally, to maintain an adequate degree of smoothness, (change in axial station $<10 \%$ to $20 \%$ is a good rule of thumb), a simple central difference averaging scheme adjusts the 'non-smooth' control points iteratively until they all meet the smoothness criteria. Note that this procedure does not specify the radial distribution of points near the cowl and centerbody surfaces. Radially packing of grid points is done independently within the PROTEUS code.

Figure 6 presents some results of the grid generation process. The initially packed and skewed mesh is shown in the above grid. This grid was smoothed so that the maximum change in streamwise packing of the points did not exceed $10 \%$. For the $10 \%$ smoothed mesh, calculations using the PROTEUS code intermittently failed. A final grid packing smoothness of $5 \%$ proved robust and was used in all subsequent PROTEUS and PARC calculations. This 5\% smoothed grid is shown in figure 4. The mesh shown is for the fine mesh. The coarse mesh was similarly developed using $5 \%$ smoothing.

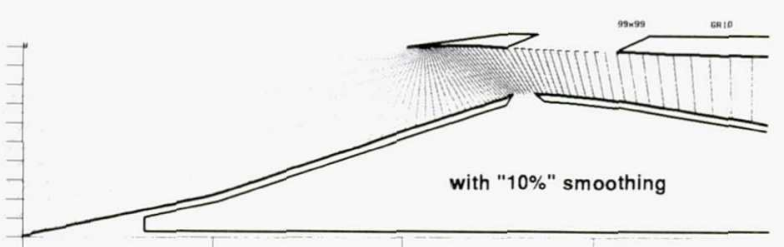

FIGURE 6., Smoothed mesh

Using this grid generation tool, the number of points in the throat bleed slot increased from 3 to 7 for the coarse mesh, (149 axial points). For the fine mesh, (447 axial points), a total of 53 points were placed in the bleed slot.

\section{Results}

Results of computational analysis for the VDC inlet are broken into eight areas. The analysis will be compared to static pressure distributions and pitot rake measurements from the fixed hardware tests. In addition to the comparison, data from the computational analysis will be presented as Mach number and pressure contour plots.

The results from the FNS analysis code will be discussed at length. The discussion of the FNS code predictions are divided into four areas: A) Euler and laminar cases, B) Turbulent cases with bleed, C) Design back-pressure case, D) Effect of cowl bleed. Along with these topics, the need and impact of cowl translation will be discussed.

\section{A. Euler Cases}

Results from the FNS analysis are based on the two similar codes, PROTEUS and PARC. Initial results were obtained just using the Euler subset of the FNS equations and using a fairly conventional mesh. The mesh for this case was uni- 
formly distributed in the radial direction and slightly packed in the streamwise direction. The grid dimensions were $99 \times 99$. This case had extrapolation outflow boundary conditions allowing the flow to reaccelerate to supersonic conditions downstream of the throat.

Mach number contours are shown in figure 7 from this case. The results were obtained with the PROTEUS code. Examination of the contours shows significant shock wave smearing in the physical domain. In fact, the cowl shock is not sharply defined, and the entire cowl compression appears to be distributed both well upstream and downstream of the shoulder. (Recall that the inlet design was for shock cancellation and focussed cowl compression at the centerbody shoulder).

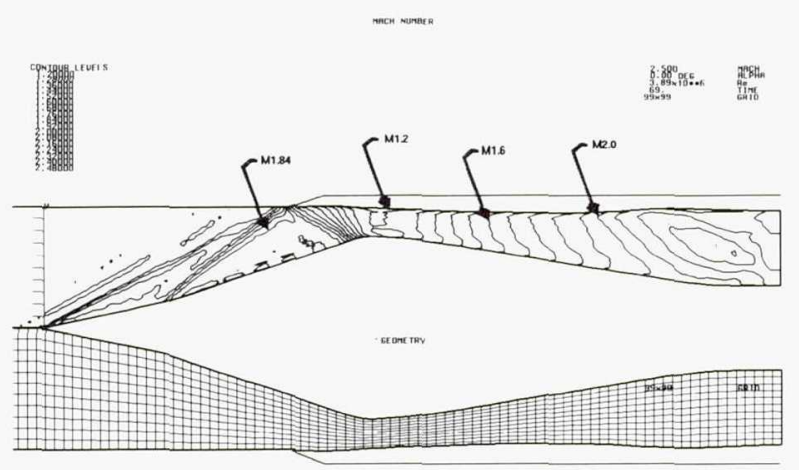

FIGURE 7., Euler solution, Mach contours, coarse grid, $99 \times 99$ points.

An effort in skewing and packing the grid as well as adding more grid points to the calculation domain was strongly motivated by the previous result. Figure 8 shows Mach number contours resulting from intermediate calculation of the inviscid flowfield with a refined mesh. Also shown is the previous calculation done on the uniform mesh. Although both of these calculations eventually unstarted, the sharpness of the shocks is clearly much better for the skewed, packed mesh.

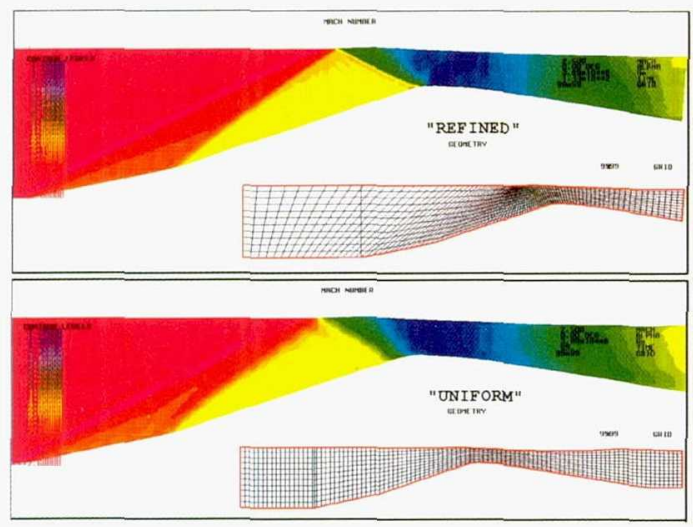

FIGURE 8., Effect of grid placement on
developing Euler solution

Calculations continued for the coarse $5 \%$ mesh for the design inlet geometry without bleed. Euler and laminar cal- culations failed since they predicted the cowl shock intersection forward of the shoulder. This forward intersection caused a separation at the centerbody surface that grew and eventually caused the inlet flow to unstart. From the fixed hardware tests, at least a $2 \%$ bleed mass flow ratio was needed to maintain a started inlet. This result might help explain why the viscous calculated flowfield unstarted. The Euler result is more puzzling, since the prior MOC and PNS calculations suggest a started, shock-on-shoulder inlet flow should have been predicted. These calculations were done by the PROTEUS code and the coarse mesh size was limited by the memory size of the available Cray-XMP supercomputer. (The YMP machine with its larger memory was not available at that time).

Restricted in mesh size, additional cases were run by first overspeeding the inlet and then by translating the centerbody. By overspeeding the inlet, the higher Mach numbers both caused lower shock angles as well as a higher throat Mach number. With the lower shock angle the intent was to cause the shock to hit downstream of the shoulder. Unfortunately, the conical centerbody shocks were also more oblique and were ingested at the cowl lip plane. Figure 9 shows Mach number contours for this case. The centerbody

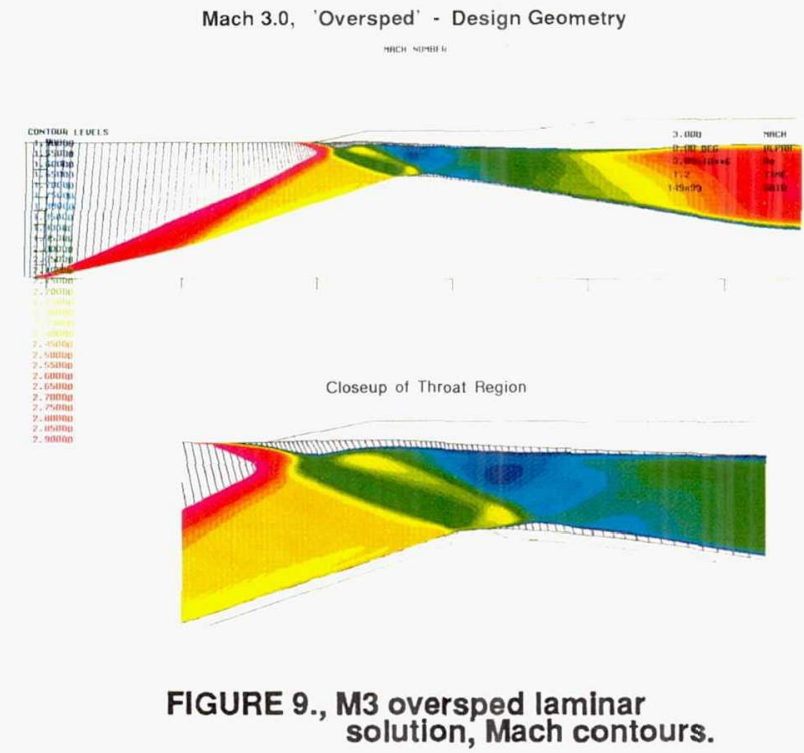

shock ingestion caused separation on the cowl surface. The multiple shocks from this cowl separation do however intersect the centerbody at, and downstream of the shoulder. For this case the cowl separation grows and eventually cause inlet flow unstart.

A similar M3 oversped case was run, but now with the centerbody translated forward $0.063 \mathrm{R}_{\mathrm{c}}$ relative to the cowl surface. The centerbody shocks were no longer ingested and the cowl boundary layer remained attached, (figure 10). Note also, the cowl shock hits well downstream of the shoulder. It passes through the strong expansion of the shoulder and causes the centerbody boundary layer to separate. This case did remain started 


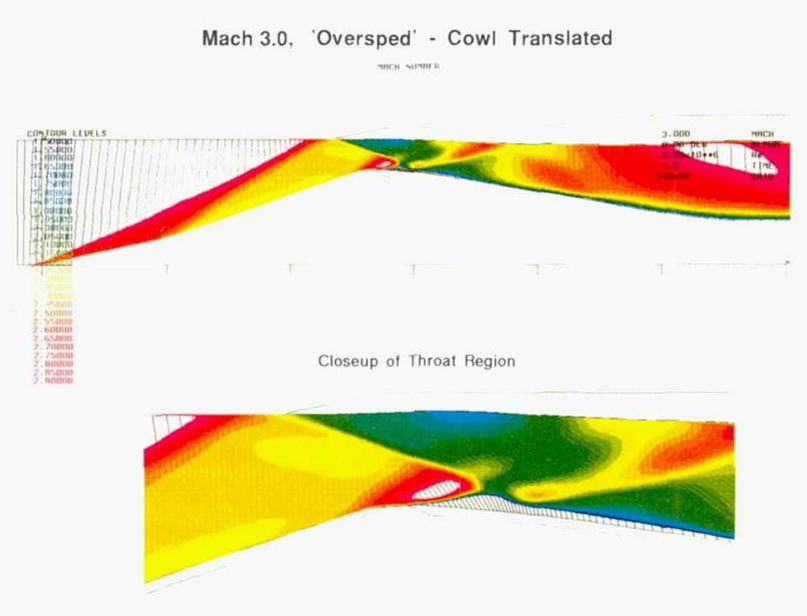

FIGURE 10., M3 laminar solution with cowl translation.

The next case attempted was at the design Mach number of 2.5 , cowl translated at $0.063 \mathrm{R}_{\mathrm{c}}$ and about $6 \%$ centerbody bleed mass flow ratio. At this time, the CRAY-YMP became available, and solution with the fine mesh was pursued. Since the exit massflow reached a constant value, this case reached a steady started inlet flow prediction. Mach number contours of figure 11 show the cowl shock hitting within the bleed slot, as well as a flow expansion caused by the bleed flow leaving the computational domain. Due to this expansion, the flow turns towards the centerbody and a fairly strong oblique shock forms as the flow hits the centerbody at the downstream edge of the bleed slot. These results were for the PROTEUS model and used the velocity profile from the Hamed and Lehnig study, reference 19, to simulate the bleed boundary.
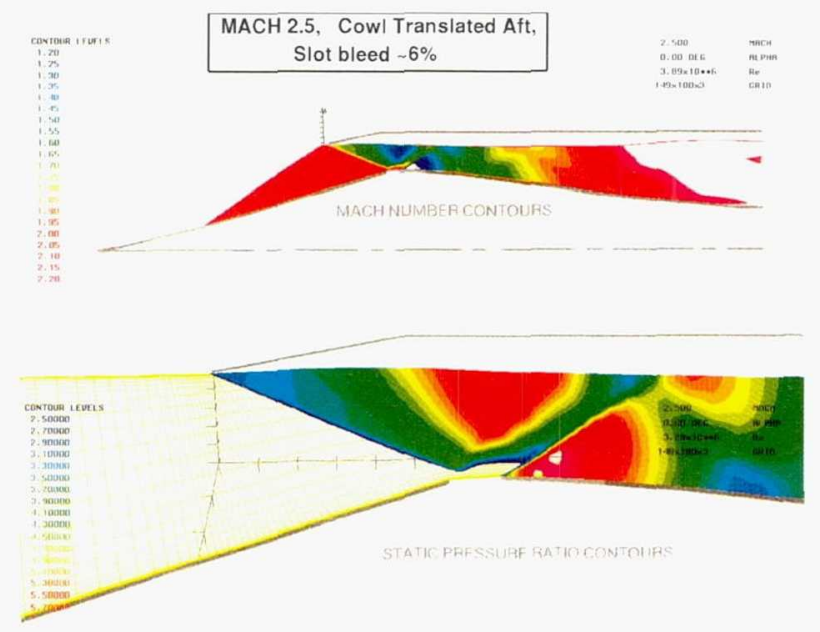

FIGURE 11, M2.5 laminar solution with cowl translation.

With these encouraging results, emphasis was shifted back to the design geometry without cowl translation. The grid was suitably modified and the earlier solution was used as initial conditions for the design geometry. Solutions were obtained for the turbulent flow case of the design geometry.

\section{B. Turbulent Case with Bleed}

As mentioned, the started laminar viscosity case with $6 \%$ centerbody bleed and cowl translation did converge in terms of exit massflow. This case was initially chosen to explore the process of back-pressuring, or changing the outflow boundary condition. For the design geometry, figure 12 shows Mach number contours in the subsonic diffuser for various computational time slices as the outflow boundary pressure is increased. The terminal shock advances forward towards the throat of the inlet. The exit static pressure ratio was set to 11.62 and global time-stepping was used when the shock approached the throat.

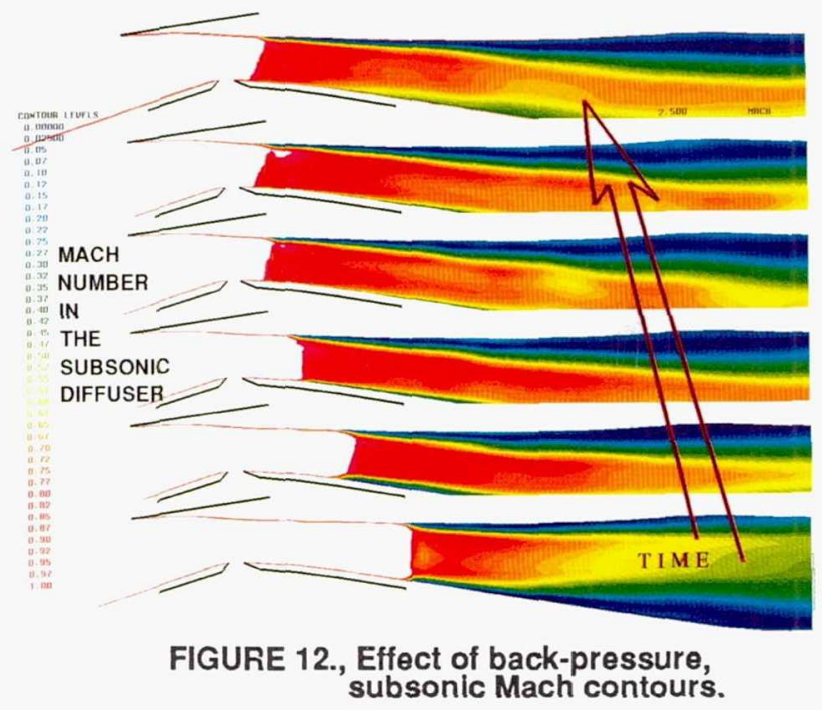

Global time-stepping locks a constant time-step to advance the solution throughout the computational domain. Local time-stepping advances the solution for each grid point at different rates depending on the local value of CFL number which sets numerical stability. Local time-steps generally converged to a steady state solution faster than global timestepping. However, this faster convergence seems to create larger oscillations in the solution when the outflow boundary condition is changed. When the terminal shock approached the throat, (critical inlet flow), even small pressure oscillations of $5 \%$ could push the shock upstream of the throat and cause the solution to unstart. The global timestepping helped damp out spurious transients in the solution induced during local time-stepping.

In setting the value of exit pressure level, guidance was gained from the experimental data. The data indicates the correct level of pressure ratio for the outflow condition ranges from: 13.7 for supercritical, 14.1 for critical, to 14.4 for "peak" or subcritical inlet flow. This data was for about $2 \%$ centerbody bleed flow and a slightly different subsonic diffuser. The diffuser had vortex generators to prevent separation installed downstream of the throat. Additional data was found in reference 2 that showed the presence of the vortex generators affected the outflow pressure ratio by only $3 \%$. This brings the above-mentioned range to: 13.3 for 
supercritical, 13.7 for critical, and 14.0 for "peak" or subcritical inlet flow. However, all of these levels of back-pressure led to unstarted flow computationally when they were suddenly imposed at the exit plane. A more conservative pressure ratio of 11.62 was arrived at by trial and error.

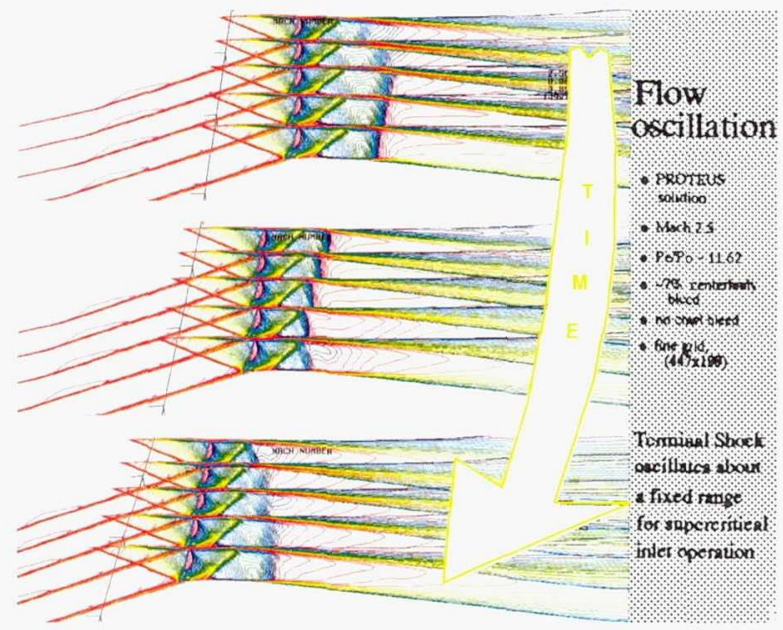

FIGURE 13., Flow oscillation, Mach contours, Pcf/Pinf $=11.62$

At this pressure ratio of 11.62 , the solution did not reach any form of steady state solution. In examining the solution, the terminal shock's final position was found to oscillate around a fixed location, figure 13. This solution was obtained using the PROTEUS code with turbulent viscosity. From the freestream entrance plane to nearly one throat height downstream of the aft edge of the centerbody bleed slot, the Mach number contours remain constant with respect to computational time. Just downstream, the terminal shock location first advances forward and then collapses back downstream. Figure 14 shows the centerbody static

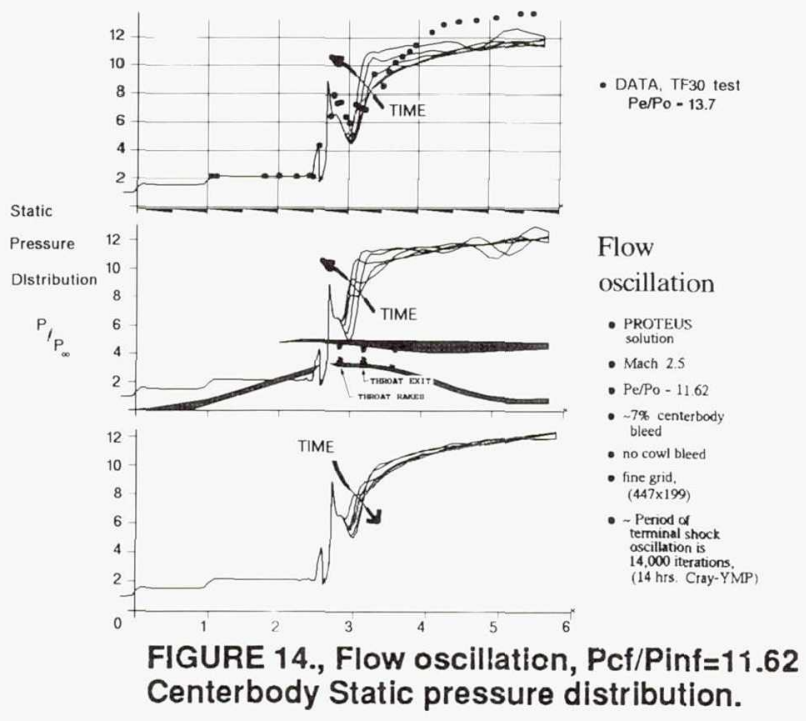

pressure distribution for these cases. Again, the shock location indicated by the sharp pressure rise around $X / R_{c}=3$ first travels upstream, then downstream. Also, note the rise is much sharper for the upstream traveling shock compared to the downstream traveling shock. The period of this oscillation took over 14,000 iterations or 14 CRAY-YMP Cpu hours to compute. Experimentally, dynamic distortion, a measure of flow unsteadiness, was found to increase at supercritical condition. This result supports the flow oscillation phenomena encountered with the FNS analysis.

Another point to mention on the centerbody pressure distribution, figure 14 , is the pressure rise at $X / R_{c} \sim 2.4$. This axial location is upstream of the shoulder, $X / R_{c}=2.5831$, and indicates the cowl shock is impinging forward of the shoulder. The data also indicates this phenomena occurs. A more detailed view of this region of the flow is discussed next.

The PARC code was run for the same case with the same grid. Comparison of Mach number contours is shown in figure 15. The contours are for a detailed region through the inlet throat. Again, upstream of the terminal shock location, agreement between the two codes is good. Evident is the cowl shock hitting slightly forward of the shoulder causing a small separation. The cowl shock reflects from this separation and then crosses back to the cowl surface. The reflection on the cowl surface is of sufficient strength to separate the cowl boundary layer and cause a Mach reflection. Downstream of the Mach reflection's normal shock, the flow is slightly subsonic but accelerates back to supersonic conditions. The PARC code resolves this phenomena more crisply than the PROTEUS code. The shock continues to reflect and coincides with the oblique shock at the aft end of the bleed slot on the centerbody surface. In the PROTEUS analysis, this oblique is weak and the flow remains supersonic downstream. The PARC code predicts a strong oblique shock that coalesces with the terminal to generate subsonic flow. For both code predictions, the terminal shock is locally unsteady. Perhaps the most important difference between the code is the speed and memory requirements. For this case, PARC used only $40 \%$ of the Cpu time per iteration and $15 \%$ of the memory.

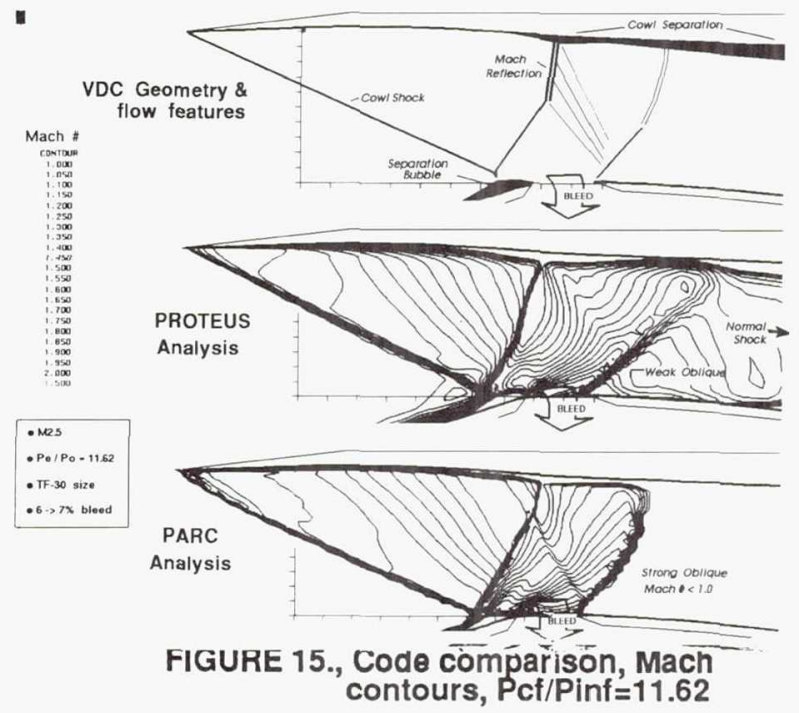

To further display the features of this flow, figure 16 shows the particle traces for this case from the PARC code analy- 
sis. The small separation forward of the centerbody shoulder bleed slot and the bleed flow exiting through the slot are clearly evident. The result also suggests a need for additional static pressure instrumentation to better quantify the extent of the separation. . This case was done with the cen-
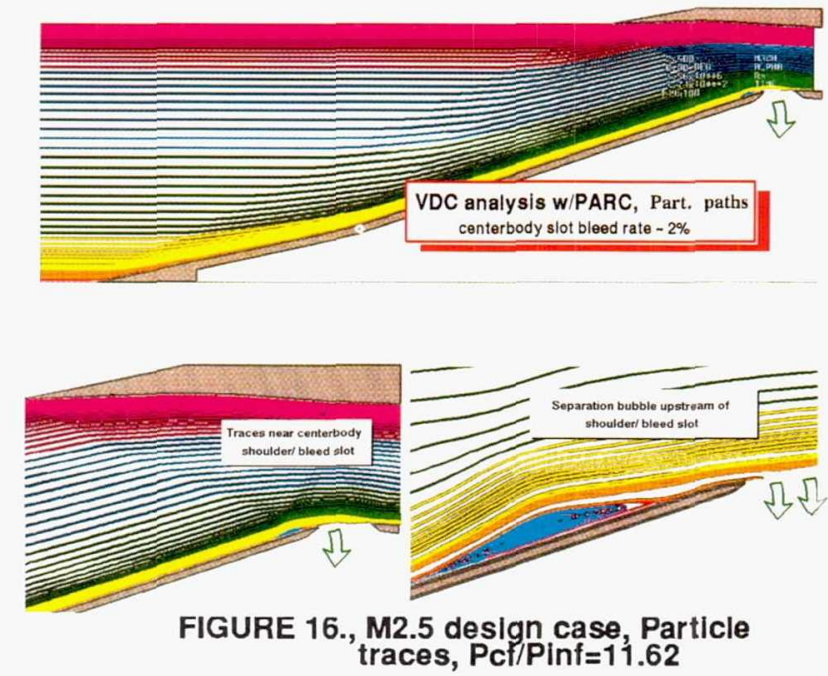

terbody bleed flow rate at $2 \%$, so its solution is directly relatable to the data.

Figure 17 shows the results of the comparison of pitot pressures between the experiment and numerical solution. The various rakes are located on figure 14. Comparison is excellent for the cowl throat rake. The flow on the cowl to this point is unaffected by separations and by the centerbody bleed, so boundary layer growth and oblique shock pressure level should be correctly modeled by the code. Pitot pressure profiles for the other two rakes show moderate agreement. These rakes are downstream of separations and the bleed slot. Therefore, they are strongly affected by phenomena that are, at best, only approximately simulated by the turbulence model and the bleed boundary condition.
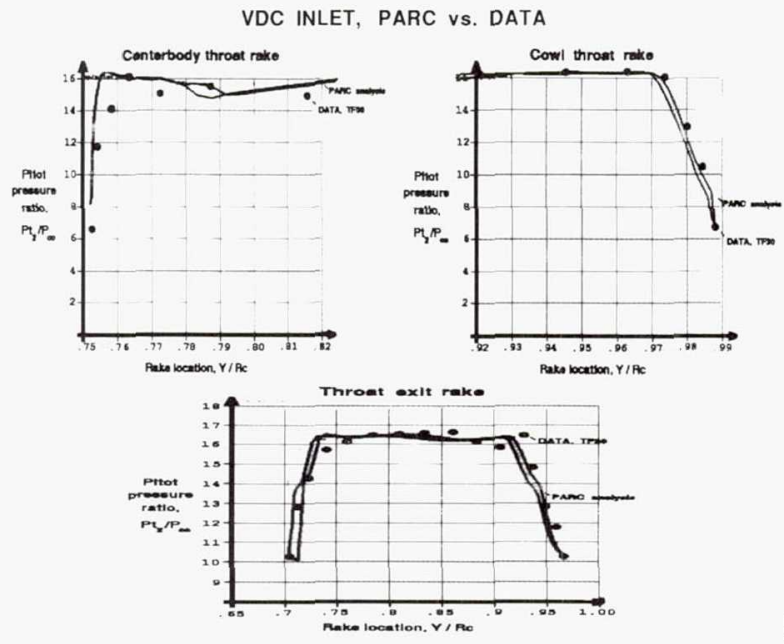

FIGURE 17., Pitot pressure rake data versus prediction.
C.

\section{Design Back-pressure Case}

The next few figures show the computations for an exit pressure ratio of 13.7 that predicts unstarted inlet flow. Figure 18 shows the static pressure distributions as the outflow boundary pressure is suddenly increased. The terminal shock pressure-rise moves upstream with time. Downstream of the shock, static pressure levels oscillated in computational time.

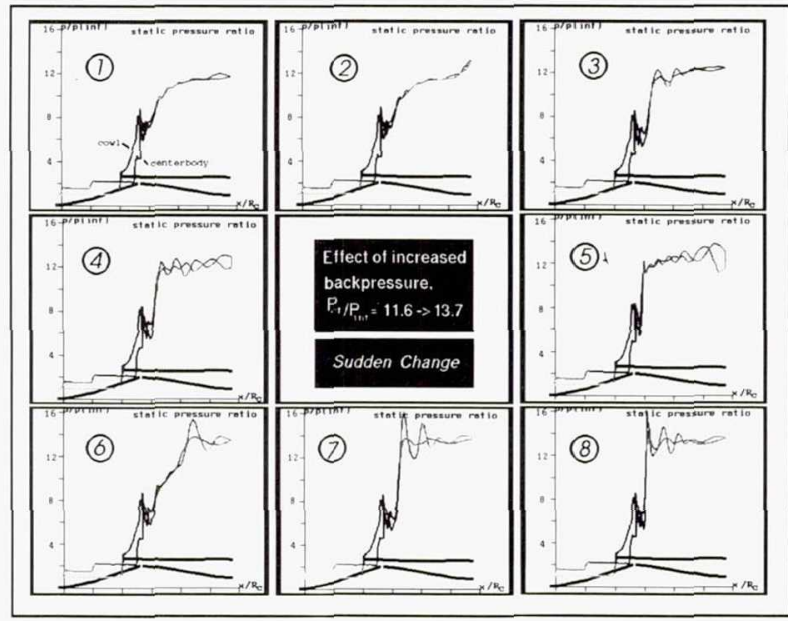

FIGURE 18., Design back-pressure, static pressures, sudden change

The plot of total pressure distribution is shown in figure 19 . These values are for a line midway between the cowl and centerbody surfaces. The problems in the transient pressure pulse are evidenced by increases in total pressure ratio. (Note, total pressure is inversely proportional to entropy for a steady ideal gas. For a transient flow, however, entropy can decrease in the streamwise direction for a moving shock, see Appendix A). If a steady state solution is ultimately sought, any increase in total pressure can be construed as an indication that the flowfield is unsteady. Since both PROTEUS and PARC are solving the unsteady NavierStokes equation, albeit inaccurately in time, the pressure oscillation can occur and extreme care must be taken to prevent overwhelming pressure oscillations.

The sequence in figure 20 shows the end result, the calculated flowfield unstarts. A total variation diminishing scheme, (TVD), which reduces numerical oscillations about shock waves, (references 17 and 18), might be a more suitable code to do inlet back-pressure studies.

Because of the extreme sensitivity of shock position to the exit pressure boundary condition, further effort was made to gradually increase exit pressure and simulate critical inlet operation. PROTEUS was chosen for this effort due to two reasons. Since exit pressure can be changed gradually over a specified number of iterations, the problem of hammershock overpressure can be greatly reduced. The secomd reason for using PROTEUS lies with its more flexible bleed 


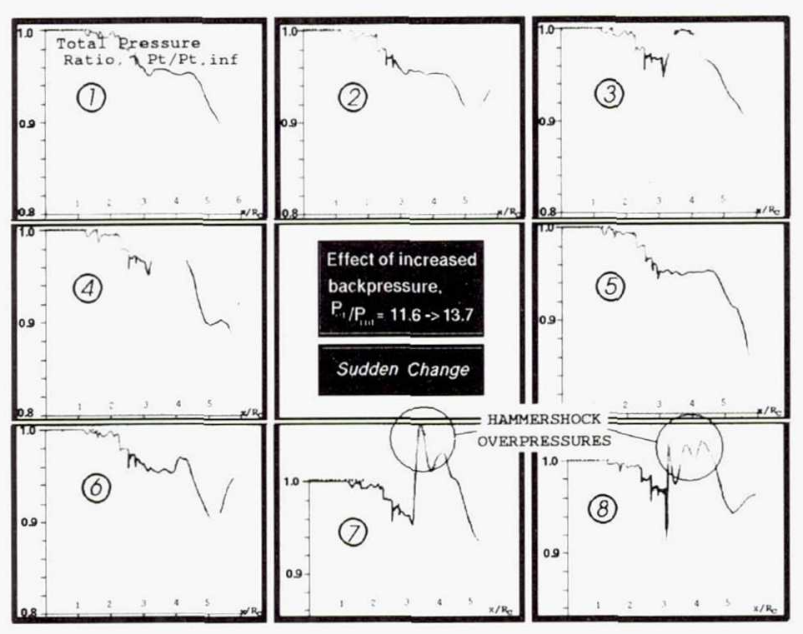

FIGURE 19., Design back-pressure, total pressures, sudden change.

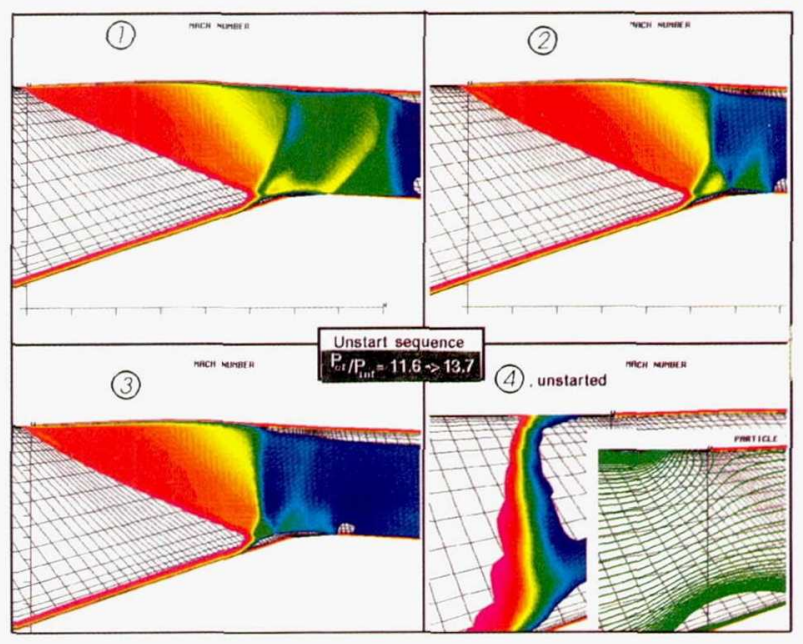

FIGURE 20., Design back-pressure, Unstart Mach contours, sudden change.

model. Both of these reasons were crucial to the successfulsimulation of critical inlet operation, figure 21 .

For this case the exit pressure was increased from 12.74 to 13.7 over 20,000 iterations. Even with this slow change of pressure a slight overpressure occurs, travels upstream, and moves the terminal shock forward onto the bleed slot. The bleed boundary condition model, which was based on Hamed's velocity profile, did allow the massflow to increase by $\sim 50 \%$ during this terminal shock/bleed interaction. The shock eventually moved back downstream to the aft edge of the bleed slot and remained stable.

Also, this case was run with slight amount of cowl translation, $X / R_{c}=0.035$. This translation was picked to position the cowl shock intersection with the centerbody downstream onto the bleed slot. The intent was to eliminate the small separation bubble upstream of the slot. The result, shown in figure 21 , was a decrease in the extent of the separation. Because of the translation, approximately $3 \%$ more flow is spilled and the internal contraction is reduced. The

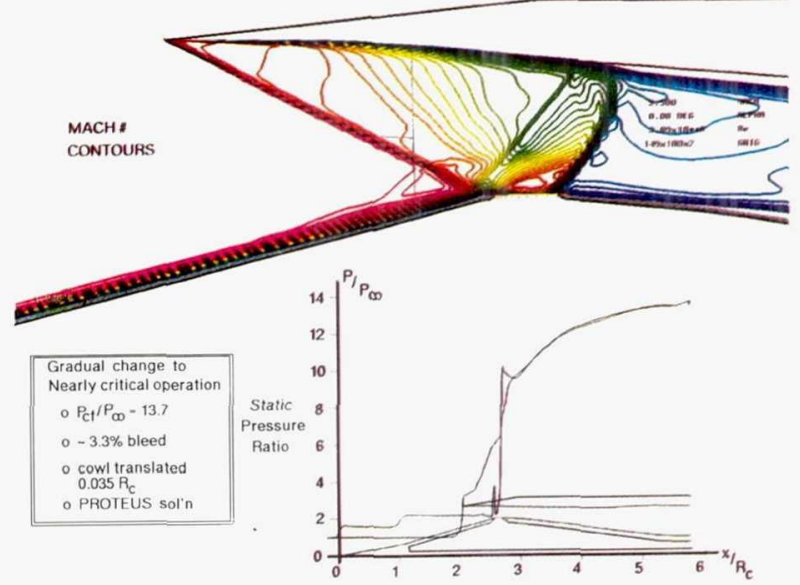

FIGURE 21. Design back-pressure, Mach contours, slow change.

Mach number contours which do not exhibit a Mach reflection are a consequence of the reduced internal contraction.

The integrated massflow was $97.5 \% \pm 0.2 \%$. Total pressure recovery was $88 \% \pm 0.2 \%$ and the bleed massflow rate was $\sim 1.9 \%$. Also shown in figure 21 is the comparison of static pressure distribution. The agreement with data is very good, the slight descrepencies are due to greater calculated loss in total pressure recovery, (the experimental recovery was $89.5 \%)$.

\section{Effect of Cowl Bleed}

In order to control the oscillation of the terminal shock, a region of cowl bleed was simulated with the PARC code by specifying mass flux through the cowl boundary. The VDC inlet's porous cowl bleed is located between $x / R_{c}=2.556$ to $x / R_{c}=3.105$. An initial run was attempted with the entire area controlled by the bleed boundary condition.

Unfortunately, this large, semi-free boundary seemed to aggravate rather than reduce the flow unsteadiness, (figure 22). In fact, the momentum vectors at the cowl bleed boundary flucuate wildly both spatially and temporally. The vectors for the case presented indicate alternating areas of blowing and bleeding through the 'bleed' boundary. In the Mach number contours, a very large separation has developed on the cowl surface due to the blowing momentum at the end of the region.

This result suggests the need for a more refined simulation of the bleed region. Limiting the extent of the bleed region may help direct the flow and reduce the areas of blowing. Compartmentalizing the bleed, or having two independently specified bleed regions, is also worthy of investigation. Further work in refining the cowl bleed is recommended, particularly because of its potentially dramatic impact on the upcoming wind tunnel testing. 


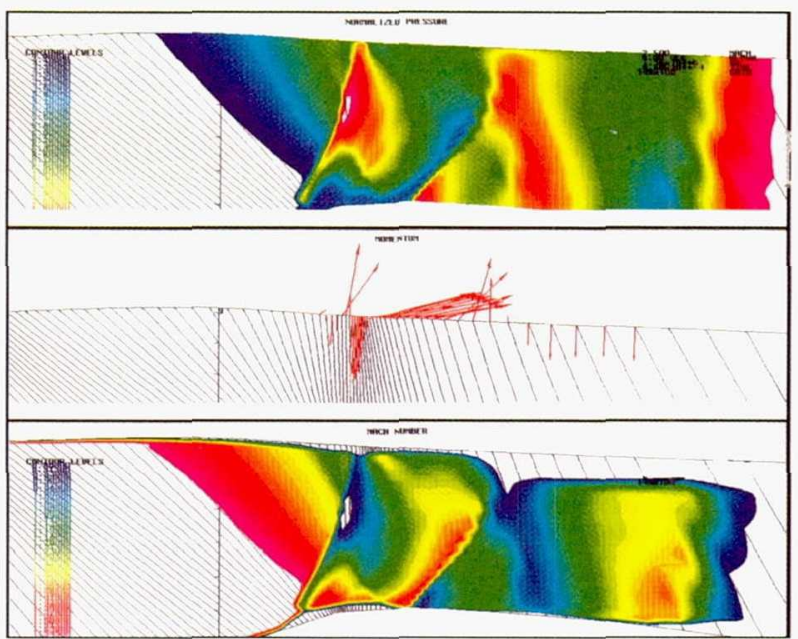

FIGURE 22., Effect of cowl bleed, entire bleed region open.

\section{$\underline{\text { V. Conclusions }}$}

\section{Summary:}

A series of analytical tools were applied to understand the flowfield in a supersonic inlet. These tools had varying degrees of success when compared to existing data from a wind tunnel test of the inlet geometry. Some of the major results are summarized below:

1) Elliptic Euler analysis failed due to instability in the centerbody flow separation, which led to an unstarted flowfield.

2) FNS viscous analysis predicted unstart for the design geometry without centerbody bleed, agreeing with experimental testing. Both analysis and testing agree that the design geometry will remain started at a bleed mass flow ratio, $\mathrm{m}_{\mathrm{bl}} / \mathrm{m}_{\mathrm{c}}$, of $2 \%$. Analysis further predicts that the inlet will remain started without bleed at a centerbody translation of $\mathrm{X} / \mathrm{R}_{\mathrm{c}}=0.065$.

3) For a supercritical inlet flowfield, FNS turbulent viscous analysis with bleed agreed well with experimental data forward of the centerbody bleed slot including a region of separated flow just upstream of the slot.

Downstream of these regions the agreement is fair, pointing out deficiencies in the bleed and turbulence modeling. These deficiencies prevented analysis of critical and peak inlet conditions.

4) FNS codes indicated an inherent unsteady flow oscillation of the terminal shock at a supercritical flow condition. This agrees with empirical experience that suggest that dynamic distortion increases as the terminal shock moves downstream from the inlet throat.

5) Both FNS codes failed to correctly predict the inlet recovery. Analytical predictions were $\sim 1.5 \%$ below measured recoveries.

6) Preliminary analysis with the PARC code indicated that a fully open cowl bleed pattern may enhance rather than eliminate flow unsteadiness and subsonic diffuser separations.

7) Analysis predicted that the flow separation upstream of the centerbody shoulder can be virtually eliminated with a centerbody translation of $\mathrm{x} / \mathrm{R}_{\mathrm{c}}=0.035$.

\section{$\underline{\text { VI.References }}$}

1. Wasserbauer, J. F.; Shaw, R. J.; and Neumann, H. E.: Design of a Very-Low-Bleed Mach 2.5 Mixed-Compression Inlet with 45 Percent Internal Contraction. NASA TM X-3135, 1975.

2.Neumann, H. E.; Wasserbauer, J. F.; and Shaw, R. J.: Performance of Vortex Generators in a Mach 2.5 LowBleed Full-Scale 45-Percent-Internal- Contraction Axisymmetric Inlet. NASA TM X-3195, 1975.

3. Wasserbauer, J. F.; Neumann, H. E.; and Shaw, R. J.: Distortion in a Full-Scale Bicone Inlet with 45 Percent Internal Contraction. NASA TM X-3133, 1975.

4.Wasserbauer, J. F.; Neumann, H. E.; and Shaw, R. J.: Performance and Surge Limits of a TF30-P-3 Turbofan Engine/Axisymmetric Mixed- Compression Inlet Propulsion System at Mach 2.5. NASA TP-2461, 1985.

5.Anderson, B. H.: Design of Supersonic Inlets by a Computer Program Incorporating the Method of Characteristics. NASA TN-D 4960, 1969.

6.Bowditch, D. N.: Some Design Considerations for Supersonic Cruise Mixed Compression Inlets. NASA TM X71460, 1973.

7. McLean, F. E.: "Future Directions of Supersonic Cruise Research", Supersonic Cruise Technology. NASA SP$472,1985$.

8. Towne, C. E.; Schwab, J. R.; Benson, T. J.; and Suresh, A,: PROTEUS Two-Dimensional Navier-Stokes Computer Code-Version 1.0. NASA TM- 102552, 1990.

9. Cooper, G. K.; Sirbaugh, J. R.: PARC Code: Theory and Usage. AEDC-TR-89-15, 1989.

10. Avva, R.; Smith, C.; and Singal, A.: Comparative Study of High and Low Reynolds Number Versions of k-e Models. AIAA Paper 90-0246, AIAA 28th Aerospace Sciences Meeting, Reno NV, January 1990. 
11. Vadyak, J.; Hoffman, J. D.; and Bishop, A. R.: Calculation of the Flow Field in Supersonic Mixed-Compression Inlets at Angle of Attack using the ThreeDimensional Method of Characteristics with Discrete Shock Wave Fitting. NASA CR-135425, 1978.

12. Weir, L. J.; Reddy, D. R.; and Rupp, G. D.: Mach 5 Inlet CFD and Experimental Results. AIAA Paper 89- 2355, July 1989.

13. Reddy, D. R.; Benson, T. J.; and Weir, L. J.: Comparison of 3-D Viscous Flow Computations of Mach 5 Inlet with Experimental Data. AIAA Paper 90-0600, 1990.

14. Rizzetta, D. P.: Numerical Simulation of a Supersonic Inlet. AIAA Paper 91-0128, 1991.

15. Chyu, W. J.; Howe, G. W.; and Shih T. I-P.: Boundary Conditions for the Bleed Opening in the Numerical Simulation of Critical Flow through Turbojet Inlets. (unpublished report)

16. Hunter, L. G.; Tripp, J. M.; and Howlett, D. G.: A Mach 2.0 Plus Supersonic Inlet Study using the NavierStokes Equations. AIAA Paper 85- 1211, 1985.

17. Shigematsu, J.; Yamamoto, K.; and Shiraishi, K.: Numerical Investigation of Supersonic Inlet using Implicit TVD Scheme. AIAA Paper 90-2155, 1990.

18. Fujimoto, A.; Niwa, N.; and Sawada, K.: Numerical Investigation on Supersonic Inlet with Realistic Bleed and Bypass Systems. AIAA Paper 91- 0127, 1991.

19. Hamed, A., and Lehnig, T.: An Investigation of Oblique Shock/Boundary Layer Bleed Interaction. AIAA 901928, 1990.

20. Pordal, H. S.; Khosla, P. K.; and Rubin, S. G.: Transient Behavior of Supersonic Flow through Inlets. AIAA 902130, 1990.

21. Hindash, I. O.; Bush, R. H,; and Cosner, R. R.: Computational Modeling of Inlet Hammershock Wave Generation. AIAA Paper 90-2005, 1990.

22. Sanders, B. W.: Dynamic Response of a Mach 2.5 Axisymmetric Inlet and Turbojet Engine with a PoppetValve-Controlled Inlet Stability Bypass System when Subjected to Internal and External Airflow Transients. NASA TP-1531, 1979.

\section{Appendix}

\section{Appendix A. Hammershock Over-pressure Analysis}

Equations are developed for the one-dimensional transient duct flow undergoing a sudden blockage at the exit. This analysis demonstrates the concept of hammershock overpressure.
The analysis for a one-dimensional transient duct flow shows that peak pressure during a transient can be substantially greater than the steady-state total pressure of the flow. This result contrasts to the three-dimensional steady-state result: total pressure can never increase in the flow direction provided no work is added to or heat is taken from the flow.

A schematic of the flow phenomena is given below, figure A.1

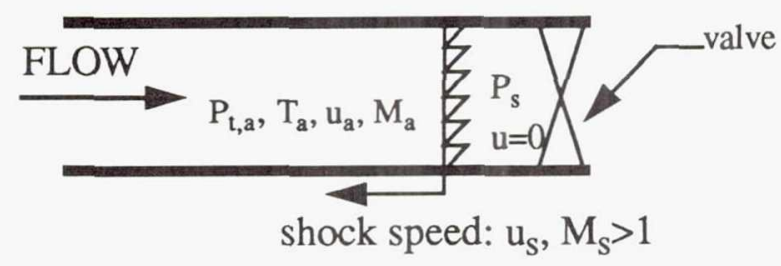

FIGURE A.1, 1D Transient duct flow

The assumptions made in this analysis are one-dimensional ideal air flow with $\gamma=1.4$. Also assumed was that zero velocity occurs after the transient and that a normal shock travels upstream at a velocity, $\mathrm{u}_{\mathrm{s}}$. The assumption of zero velocity ahead of the blockage valve, (or stalled engine), is a reasonable simplification, but it does not represent the worst case scenario. Flight experience has proven that during a hammershock transient, reverse flow can occur in the propulsion system, i.e. flames shoot out of the inlet! For this severe situation, over-pressures beyond that indicated by the following simple analysis can occur.

The initial frame of reference is fixed to the duct walls. Now, if we change our reference frame to traveling with the moving normal shock, the steady-state normal shock relations can be applied. In the new frame of reference, the Mach number ahead of the shock becomes:

$$
M_{a s}=\frac{\left(u_{a}+u_{s}\right)}{\sqrt{\gamma R T_{a}}}
$$

The Mach number ahead of the shock in the wall fixed frame, $M_{a}$, is related to the shock fixed frame Mach number by:

$$
M_{a}=M_{a s}-\left(\frac{M_{a s}^{2}+5}{6 M_{a s}}\right)
$$

The pressure ratio, downstream static to upstream total, is thus:

Also, the Mach number downstream of the shock in the wall fixed frame, $M_{s}$, is related to the shock fixed frame Mach number by: 


$$
\begin{aligned}
& \frac{P_{s}}{P_{t, a}}=\frac{7 M_{a s}^{2}-1}{6}\left[\frac{5}{M_{a}^{2}+5}\right]^{3.5} \\
& M_{s}=\sqrt{\left[\frac{5+M_{a s}^{2}}{\left[\left(7 M_{a s}^{2}-1\right) \frac{M_{a s}^{2}+5}{36 M_{a s}^{2}}\right.}-5\right]}
\end{aligned}
$$

If we use $M_{a s}$ as a parametric variable, we can solve the equations for pressure ratio and $\mathrm{M}_{\mathrm{a}}$ and plot the resulting relationship, (figure A.2)

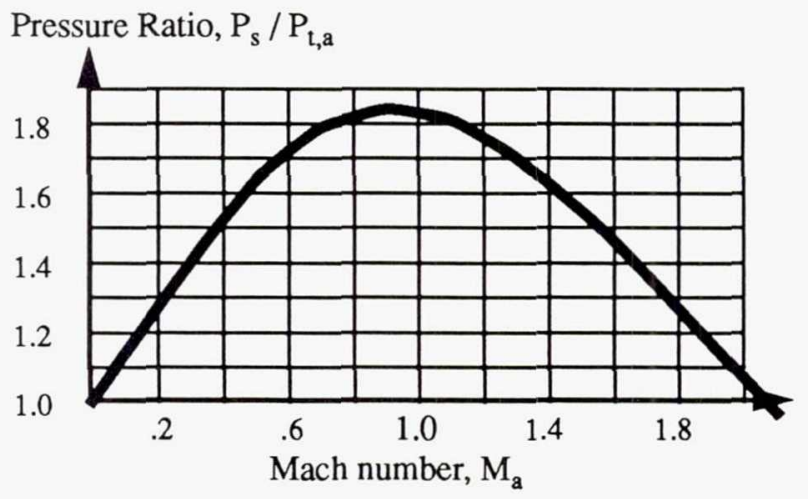

FIGURE A.2, Hammershock Over-Pressure Ratio

Note that the maximum over-pressure reaches a level of 1.84 times the freestream total pressure at slightly less than sonic conditions in the duct, figure A.2. As the Mach number further increases, the over-pressure begins to decrease as the normal shock losses overwhelm the transient increase in total pressure.

A typical supersonic inlet has nearly sonic conditions in the throat. This analysis clearly shows how over-pressures greatly exceeding the freestream total may develop during transient inlet phenomena. Therefore, when an engine stalls downstream of an inlet, or when the compressor face boundary condition is rapidly changed in a computational study, hammershock over-pressures are produced.

\section{Appendix B. Axisymmetric Governing Equations}

The Full Navier-Stokes equations for axisymmetric flow are given along with assumptions used in analyzing the VDC Inlet. Also presented are the equations for the BaldwinLomax algebraic turbulence model.

The analysis used in the FNS codes for the VDC Inlet study are the well known Navier-Stokes equations written in cylindrical coordinates for axisymmetric flow. These equations are somewhat more complicated than the classic twodimensional planar equations due to the dependence of various terms on the radial direction. In vector notation the axisymmetric equations with swirl become:

$\frac{\partial}{\partial t}(r \bar{Q})+\frac{\partial}{\partial x}(r \bar{E})+\frac{\partial}{\partial r}(r \bar{F})+H=\frac{\partial}{\partial x}\left(r \bar{E}_{V}\right)+\frac{\partial}{\partial x r}\left(r \bar{F}_{V}\right)+H_{V}$

Unsteady terms:

$$
\bar{Q}=\left[\rho \rho \mu \rho \rho w E_{T}\right]^{T}
$$

Axial derivatives:

$$
\bar{E}=\left[\begin{array}{c}
\rho u \\
\rho u^{2}+p \\
\rho u v \\
\rho u w \\
\left(E_{T}+p\right) u
\end{array}\right]
$$

Radial derivatives:

$$
\bar{F}=\left[\begin{array}{c}
\rho v \\
\rho u v \\
\rho u^{2}+p \\
\rho v w \\
\left(E_{T}+p\right) v
\end{array}\right]
$$

Swirl derivatives:

$$
\bar{H}=\left[\begin{array}{c}
0 \\
0 \\
-\left(\rho w^{2}+p\right) \\
\rho v w \\
0
\end{array}\right]
$$


Axial viscous derivatives:

$$
\overline{E_{V}}=\frac{1}{R e_{r}}\left[\begin{array}{c}
0 \\
\tau_{x x} \\
\tau_{x r} \\
\tau_{x \theta} \\
u \tau_{x x}+v \tau_{x r}+w \tau_{x \theta}-\frac{1}{P r_{r}} q_{x}
\end{array}\right]
$$

Radial viscous derivatives:

$$
\overline{F_{V}}=\frac{1}{R e_{r}}\left[\begin{array}{c}
0 \\
\tau_{x r} \\
\tau_{r r} \\
\tau_{r \theta} \\
u \tau_{x r}+v \tau_{r r}+w \tau_{r \theta}-\frac{1}{P r_{r}} q_{r}
\end{array}\right]
$$

Swirl viscous derivatives:

$$
\overline{H_{V}}=\frac{1}{R e_{r}}\left[\begin{array}{c}
0 \\
0 \\
-\tau_{\theta \theta} \\
\tau_{r \theta} \\
0
\end{array}\right]
$$

Due to the extra complexity introduced by the axisymmetric terms, the strong conservation law form of the equations is lost. The viscous and heat transfer terms are:

$$
\begin{gathered}
\tau_{x x}=2 \mu \frac{\partial u}{\partial x}+\lambda\left[\frac{\partial u}{\partial x}+\frac{1}{r}\left(\frac{\partial(r v)}{\partial r}\right)\right] \\
\tau_{r r}=2 \mu \frac{\partial v}{\partial x}+\lambda\left[\frac{\partial u}{\partial x}+\frac{1}{r}\left(\frac{\partial(r v)}{\partial r}\right)\right] \\
\tau_{\theta \theta}=2 \mu \frac{v}{r}+\lambda\left[\frac{\partial u}{\partial x}+\frac{1}{r}\left(\frac{\partial(r v)}{\partial r}\right)\right] \\
\tau_{x r}=\mu\left(\frac{\partial u}{\partial r}+\frac{\partial v}{\partial x}\right) \\
\tau_{x \theta}=\mu \frac{\partial w}{\partial x}
\end{gathered}
$$

$$
\begin{gathered}
\tau_{r \theta}=\mu\left(\frac{\partial w}{\partial r}+\frac{w}{r}\right) \\
q_{x}=-k \frac{\partial T}{\partial x} \\
q_{r}=-k \frac{\partial T}{\partial r}
\end{gathered}
$$

In the equations, $x, r$, and $\theta$ are the axial, radial and circumferential coordinate directions, respectively. The velocity components: $\mathrm{u}, \mathrm{v}$ and $\mathrm{w}$, are along those respective directions. The equations have been nondimensionalized by reference quantities of length, velocity, density, temperature, viscosity, and thermal conductivity. Pressure and total energy are

divided by $\rho_{r} u_{r}$, and time by $\frac{L_{r}}{u_{r}}$.

The reference Reynolds and Prandtl numbers are thus defined as:

$$
R e_{r}=\frac{\rho_{r} u_{r} L_{r}}{\mu_{r}}
$$

$$
\operatorname{Pr}_{r}=\frac{\mu_{r} u_{r}^{2}}{k_{r} T_{r}^{2}}
$$

The above equations, which are written in Cartesian coordinates, are then transformed to a general coordinate system. Finite difference techniques are then applied to discretize these equations. The Beam and Warming method is used to difference the equations in time. For both the PROTEUS and PARC codes, first order accurate time differencing was used. Also, the spatial derivatives were centrally differenced. Details of the implementation of the differencing schemes of the two codes are given in references $8,9 \& 10$.

The equations are valid for laminar or Reynolds time-averaged turbulent flows. For the viscous terms, $\mu, \lambda$ and $\mathrm{k}$ represent effective coefficients for turbulent shear flow. The Baldwin-Lomax turbulence model is used by both codes and, for wall-bounded flows, is given by:

$$
\mu_{\text {tot }}=\mu_{\text {lam }}+\mu_{\text {turb }}
$$

$$
\mu_{\text {turb }}=\left(\begin{array}{ll}
\left(\mu_{t}\right)_{\text {inner }}, & y_{n} \leq y_{b} \\
\left(\mu_{t}\right)_{\text {outer }}, & y_{n}>y_{b}
\end{array}\right)
$$


for free shearing turbulent flows, $\mu_{t}=\left(\mu_{t}\right)_{\text {outer }}$. $y_{n}$ is the distance normal to the wall for bounded flows or the minimum distance to the local extrema of velocity magnitude for free shear flows. $y_{b}$ is the minimum value of $y_{n}$ at which $\left(\mu_{t}\right)_{\text {inner equals }}\left(\mu_{t}\right)_{\text {outer }}$. For the PROTEUS code an averaging procedure is used if the shearing flows associated with the two walls merge. The PARC code uses the standard implementation strategy.

The standard Baldwin-Lomax outer region is given by:

$$
\left(\mu_{t}\right)_{\text {outer }}=K C_{c p} \rho F_{\text {Kleb }} F_{\text {wake }}
$$

where $\mathrm{K}=0.0168, \mathrm{C}_{\mathrm{cp}}=1.6$, and $\mathrm{F}_{\text {wake }}$ is given by

$$
\begin{gathered}
F_{\text {wake }}=\min \left(\begin{array}{c}
y_{\max } F_{\max } \\
C_{w k} V_{d i f f}^{2} \frac{y_{\max }}{F_{\max }}
\end{array}\right) \\
\bar{V}_{\text {diff }}=\max \sqrt{\left(u^{2}+v^{2}+w^{2}\right)}-\min \sqrt{\left(u^{2}+v^{2}+w^{2}\right)} \\
F\left(y_{n}\right)=\left(\begin{array}{c}
y_{n}|\bar{\Omega}|\left(1-e^{-y+} / A^{+}\right) \text {for wall-bounded flow } \\
y_{n}|\bar{\Omega}| \text { for free shear flow }
\end{array}\right)
\end{gathered}
$$

$F_{\max }$ is the maximum of $F\left(y_{n}\right)$ and $y_{\max }$ is the value of $y_{n}$ at this position.

$$
\begin{gathered}
|\bar{\Omega}|=\sqrt{\left(\frac{\partial w}{\partial r}+\frac{w}{r}\right)^{2}+\left(\frac{\partial w}{\partial x}\right)^{2}+\left(\frac{\partial v}{\partial x}-\frac{\partial u}{\partial r}\right)^{2}} \\
y^{+}=\frac{\sqrt{\tau_{\text {wall }} \rho_{\text {wall }}} y_{n}=\frac{\sqrt{\mu_{\text {wall }}|\bar{\Omega}|_{\text {wall }} \rho_{\text {wall }}}}{\mu_{\text {wall }}} y_{n}}{\mu_{\text {wall }}} \\
F_{\text {Kleb }}=\frac{1}{\left[1+B\left(\frac{C_{\text {Kleb }} y_{n}}{y_{\text {max }}}\right)^{G}\right]}
\end{gathered}
$$

and $\mathrm{C}_{\mathrm{wk}}=0.25, \mathrm{~A}^{+}=26.0, \mathrm{~B}=5.5, \mathrm{C}_{\mathrm{Kleb}}=0.3$

The standard Baldwin-Lomax inner region is given by:

$$
\left(\mu_{t}\right)_{\text {inner }}=\rho l^{2}|\bar{\Omega}|
$$

$$
l=\kappa y_{n}\left(1-e^{-y^{+} / A^{+}}\right)
$$

where $K$ is the Von Karman constant usually taken as 0.4. Also to find the effective thermal coefficient, the Reynolds analogy and a turbulent Prandtl number, $\mathrm{Pr}_{\text {turb }}$, of 0.9 was used:

$$
k_{\text {turb }}=\frac{c_{p} \mu_{t u r b}}{P r_{\text {turb }}}
$$

Finally, the second coefficient of viscosity is given by:

$$
\lambda_{\text {turb }}=-\frac{2}{3} \mu_{t u r b}
$$

In the analysis of the VDC Inlet the swirl velocity, w, was assumed to be zero and the total enthalpy was assumed to be constant. Therefore the circumferential and energy equations drop out of the coupled matrix of nonlinear partial differential equations, considerably reducing the complexity of the computation. Also assumed for the equation of state is that the airflow behaves as an ideal gas with the ratio of specific heats, $\gamma$, equal to 1.4 . Also Sutherland's viscosity relation for air is used:

$$
\mu_{\text {lam }}=T^{3 / 2} \frac{\left(1+T_{\text {suth }}\right)}{\left(T+T_{\text {suth }}\right)}
$$

where $\mathrm{T}_{\text {suth }}$ is the nondimensional Sutherland temperature. 


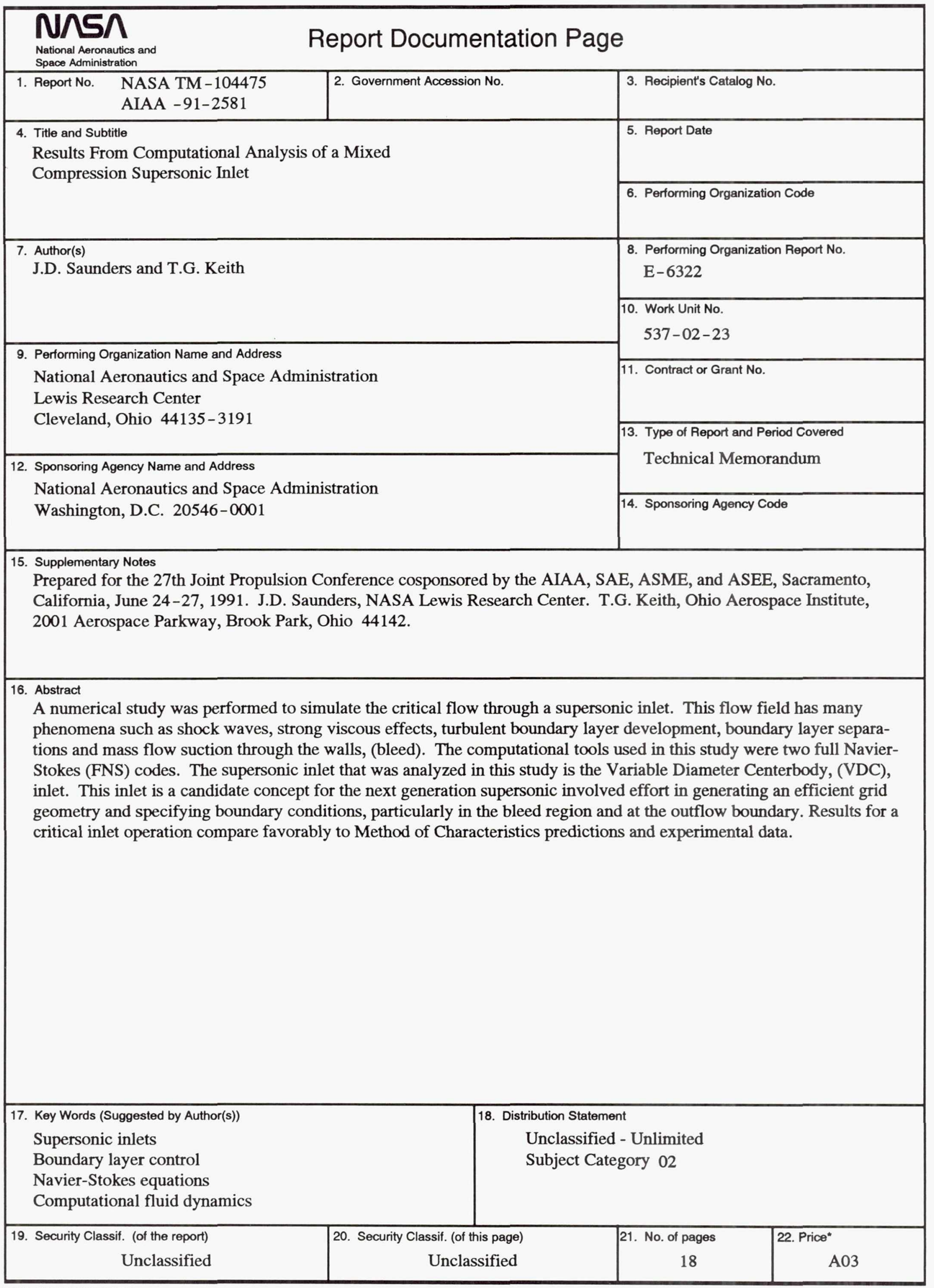

